\title{
Spontaneous Rupture of Membranes
}

National Cancer Institute

\section{Source}

National Cancer Institute. Spontaneous Rupture of Membranes. NCI Thesaurus. Code C92888.

A rupture of the fetal membranes that is not concurrent with or immediately following a digital exam or other transvaginal intervention involving the amniotic membrane. 